\title{
Preferences of color and lip position for facial attractiveness by laypersons and orthodontists
}

\author{
This article was published in the following Dove Press journal: \\ Patient Preference and Adherence \\ 18 March 2016 \\ Number of times this article has been viewed
}

\author{
Qingjuan Shi' \\ Hong Zheng ${ }^{2}$ \\ Rongdang $\mathrm{Hu}^{\prime}$ \\ 'Department of Orthodontics, \\ Hospital of Stomatology, Wenzhou \\ Medical University, ${ }^{2}$ Department \\ of Stomatology, People Hospital of \\ Wenzhou, Wenzhou, People's Republic \\ of China
}

Background: Previous studies have reported some evaluation methods about profiles, but so far, they have no consistent agreement on the esthetic profiles of color images. Thus, the aim of this study was to determine whether the judges have different preferences about the color of the photograph and lip position for esthetic profiles when comparing a Chinese boy and girl.

Methods: The photographic records of a Chinese boy and girl with a good balanced profile were randomly selected. The images of the patients' profile were altered to produce silhouettes and black and white and color photographs (a total of six images). After evaluation by the judges, the best two photographs of the boy and girl were used to produce images of anterior-posterior lip positions with $-6,-4,-2,0,+2,+4$, and $+6 \mathrm{~mm}$ in relation to the esthetic plane, which was created by Ricketts. The judges were invited to enumerate the images in the order in which they considered the most attractive.

Results: The chromophotograph was chosen as the best way to express the facial profile in both the boy and girl. The profiles with a deviation of $-4 \mathrm{~mm}$ in the boy and a deviation of $-2 \mathrm{~mm}$ in the girl from line $\mathrm{E}$ were considered as the most attractive, and the image with a deviation of $+6 \mathrm{~mm}$ from the normal line $\mathrm{E}$ was considered the least attractive. There were statistically significant differences between the preferences of the profiles of the boy and girl; the same results were recorded in the variables educational background and clinic role of the judges.

Conclusion: The chromophotograph was considered as the best way to evaluate the esthetic profiles, and the judges preferred the boy with a concave profile than the concave profile of the girl.

Keywords: orthodontic, esthetic, chromophotograph

\section{Background}

As we all know, a person with an attractive appearance has a sense of superiority and an easy to acquire good first impression. Therefore, a great emphasis is placed on the soft tissue and dental anomalies in the clinic. ${ }^{1}$ In addition to good dental intercuspation, orthodontists and patients seek to obtain a harmonious facial profile, ${ }^{2-4}$ and especially focus on the position of the lip. ${ }^{5}$ Lip position is an important element when one intends to reposition the teeth in the anterior or posterior direction, and this factor has a great influence on a balanced facial profile. ${ }^{6}$

Many studies have reported that the structure of the bone/dental and soft tissue profile in the Chinese are more protrusive in comparison with the pattern for the Caucasian. ${ }^{7,8}$ Given this, it is common for the Chinese to seek orthodontic treatment to improve their facial profile and reduce the protrusion of anterior teeth. An ideal beauty profile is of great importance in orthodontic treatments. ${ }^{6}$ The esthetic plane created by Ricketts is broadly used, among the kinds of angles and lines, because of its easy application and many studies have provided much data to evaluate it. ${ }^{6-8}$ 
Previous studies have reported some evaluation methods about profiles. Loi et $\mathrm{al}^{9}$ evaluated a series of varying lower facial vertical proportion profiles of the Japanese adults with silhouettes. Pithon et $\mathrm{al}^{5}$ and Hockley et $\mathrm{al}^{6}$ used silhouettes and photographs to evaluate the profile of Americans. Kuroda et al $^{10}$ determined the most attractive profile by varying the anteroposterior skeletal position with black and white photographs. An attractive face is a balanced and complementary match of the prominence of forehead, eyes, nose, lips, and ears, together with a concordance of the jaws and teeth coverage along with the different kinds of colorful skin and hair. ${ }^{11}$ We live in a world of color, and through the camera lens can be seen all the colors of objects. But various scholars have applied contour lines, ${ }^{12}$ silhouettes ${ }^{5,6,9}$ or black and white photographs $s^{6,10}$ to analyze profiles. However, this is different to real life. To date, there is no consistent agreement of the effect of color image on profile evaluation. In addition, the sex difference of the profile evaluation was not previously mentioned.

Thus, the aim of the present study was to assess whether there is a difference among the silhouette, black and white photograph, and color photograph on evaluating the facial profile. We also want to determine which anteroposterior lip position related to the Ricketts' line $\mathrm{E}$ is regarded as the most attractive, and whether judges have different preferences for esthetic profiles when comparing between a Chinese boy and girl.

\section{Methods}

\section{Ethics}

Ethics approval was obtained from the Ethics Board of the Hospital of Stomatology, Wenzhou Medical University. Informed consent for the study was obtained from all participants.

\section{Patients}

We collected 50 profile images of a good balanced profile (25 Chinese girls and 25 boys) before they received treatment at the Department of Orthodontics of the School \& Hospital of Stomatology Wenzhou Medical University. The inclusion criteria for selecting a good balanced profile photograph are as follows: 1) an age range of 14-20 years; 2) Chinese patients; 3) no excessive visible hair, makeup, facial, or surrounding ornamentation; 4) no hat, spectacles, or other accessories covering part of the face; and 5) skeletal class I, angle class I, less than $4 \mathrm{~mm}$ gap or crowding, and a straight profile.

\section{Image processing}

The image of the initial profile of the boy was digitally altered to the corresponding silhouette and black and white photograph by Photoshop CS4, the same as the girl. In all, the six modified photographs were placed in a set in a single slide. The evaluators could stipulate a score from 0 to 10 (visual analog scale) when presented with the individualized modified photographs by a random sequence. The images, mounted in a specific program (Microsoft Office PowerPoint 2010), were presented to the evaluators on a portable computer one by one. A total of 250 evaluators were included.

After evaluation by the judges, the two highest scores of images from the boy and girl group were produced as a series of images by varying the lip position with $2 \mathrm{~mm}$ uniformly. All the alterations were limited to the horizontal dimension, and there were no alterations in the vertical height. The structures transformed were the soft tissues below the subnasal points and above the mentolabial sulcus. The image was changed in relation to Ricketts' line E, producing anterior-posterior positions of $-6,-4,-2,0,+2,+4$, and $+6 \mathrm{~mm}$ in the upper and lower lip synchronously. There were six images of team girl and six images of team boy in total. Finally, all the images were evaluated by the judges in the same way as above.

\section{The judges}

The evaluators consisted of 100 Chinese laypersons who were students at Wenzhou Medical University in different undergraduate programs, 50 orthodontic doctors, 50 patients, and 50 parents who received orthodontic treatment at the Orthodontic Clinic of the School \& Hospital of Stomatology, Wenzhou Medical University. An information sheet describing the research was handed to each evaluator at the beginning of the presentation; evaluators were shown slides of the images they were going to evaluate and asked to stipulate each profile based on her or his criteria of the facial attractiveness of the subject. They were told the time considered necessary to stipulate the score but were instructed not to go back to slides they had already evaluated, and to finish the evaluation independently.

\section{Data analysis}

SPSS software (SPSS Inc., Chicago, IL, USA) (version 13.0) was used to analyze the data. The mean of the score results was determined in order to find out whether there were specific preferences for the color of the photograph and the facial profile in the two teams. Differences among the scores for the silhouette, black and white photograph, and chromophotograph were tested by the Wilcoxon test. The Mann-Whitney test was used to compare among the evaluation scores according to sex, age, undergraduate degree, and clinical role. For all statistical analyses, a level of significance of $5 \%(P<0.05)$ was adopted. 


\section{Results}

Two subjects used for photographic alteration are exhibited here. Their profilometric values of hard and soft tissue were within the normal range (Tables 1 and 2), and especially the distance of their upper and lower lip related to the line $\mathrm{E}$ was also within the normal range (Table 2).

The description of the evaluators is shown in Table 3. Most participants were female undergraduates and in a young age group. The evaluators were comprised of all kinds of people who emphasize the profile in the clinic, especially the patients and their parents.

The images, Figures 1 and 2, show all the color variations of the facial profile of the boy and girl. All 250 evaluators reported the obvious perceivable differences among the chromophotograph and black and white photographs and silhouettes of the boy and girl (Table 4). The group of chromophotographs had the highest mean in both the boy $(5.47 \pm 1.53)$ and girl (5.93 \pm 1.93$)$. The group of black and white photographs had the lowest mean in both the boy $(2.86 \pm 1.91)$ and girl $(3.12 \pm 2.21)$. The scores in the girl are higher than the boy in general. There were statistically preferential differences among the group of chromophotographs, black and white photographs, and silhouettes according to the Wilcoxon test $(P<0.001)$, and the teams of the boy and girl also had obvious statistical differences according to the Mann-Whitney test $(P<0.001)$.

The modified images of chromophotographs of the boy with different lip positions are presented in Figure 3, and the varied images of the girl are shown in Figure 4.

Table I Values for hard tissue analysis

\begin{tabular}{|c|c|c|c|c|}
\hline Measurements & Normal & $\begin{array}{l}\text { Standard } \\
\text { deviation }\end{array}$ & Boy & Girl \\
\hline $\mathrm{SNA}^{\circ}$ & 83.13 & 3.6 & 82.1 & 81.5 \\
\hline $\mathrm{SNB}^{\circ}$ & 79.65 & 3.2 & 79.8 & 80.4 \\
\hline $\mathrm{ANB}^{\circ}$ & 3.48 & 1.69 & 2.3 & I.I \\
\hline SN-MP & 32.85 & 4.21 & 33.65 & 34.42 \\
\hline$Y$-axis ${ }^{\circ}$ & 63.54 & 3.23 & 65.43 & 63.32 \\
\hline S-Go/N-Me & 65.86 & 3.83 & 66.21 & 65.87 \\
\hline ANS-Me/N-Me & 53.32 & 1.84 & 54.65 & 53.21 \\
\hline Ul-LI & 126.96 & 8.54 & 126.50 & 125.3 \\
\hline UI-SN & 75.38 & 6.02 & 76.2 & 75.2 \\
\hline Ul-NA, mm & 4.05 & 2.32 & 4.03 & 3.80 \\
\hline Ul-NA ${ }^{\circ}$ & 21.49 & 5.92 & 22.30 & 21.50 \\
\hline LI-NB, mm & 5.69 & 2.05 & 6.10 & 5.50 \\
\hline LI-NB ${ }^{\circ}$ & 28.07 & 5.58 & 27.6 & 28.1 \\
\hline LI-MP & 96.3 & 5.8 & 96.1 & 96.0 \\
\hline
\end{tabular}

Abbreviations: $\mathrm{SNA}^{\circ}$, sella-nasion to $\mathrm{A}$ point angle; $\mathrm{SNB}^{\circ}$, sella-nasion to $\mathrm{B}$ point angle; $\mathrm{ANB}^{\circ}, \mathrm{A}$ point-nasion to $\mathrm{B}$ point angle; $\mathrm{SN}-\mathrm{MP}^{\circ}$, sella-nasion to mandibular plane angle; $Y$ Axis ${ }^{\circ}$, sella gnathion to frankfurt horizontal plane; $S$, sella turcica; Go, gonion; N, nasion; Me, menton; ANS, anterior nasal spine; $\mathrm{UI}-\mathrm{LI}^{\circ}$, upper incisor to lower incisor angle; $\mathrm{UI}-\mathrm{SN}^{\circ}$, angle between upper incisor and sella-nasion line; $\mathrm{UI}$ $\mathrm{NA}$, distance from upper incisor to $\mathrm{NA}$ line; $\mathrm{UI}-\mathrm{NA}^{\circ}$, angle between upper incisor to NA line; LI-NB, distance from lower incisor to NB line; $\mathrm{LI}-\mathrm{NB}^{\circ}$, angle between lower incisor to NB line; LI-MP ${ }^{\circ}$, angle between lower incisor and mandibular plane.
Table 2 Values for soft tissue analysis

\begin{tabular}{lllll}
\hline Measurements & Normal & $\begin{array}{l}\text { Standard } \\
\text { deviation }\end{array}$ & Boy & Girl \\
\hline UL-EP, mm & $-\mathrm{I} .4$ & $\mathrm{I} .87$ & -0.04 & -0.45 \\
LL-EP, mm & 0.6 & 1.87 & +0.25 & -0.03 \\
Z-angle & 67.3 & 6.38 & 67.6 & 68.2 \\
Facial angle & 7.3 & 4.4 & 7.1 & 7.9 \\
Nasolabial angle & 103.5 & 6.8 & 104.5 & 103.2 \\
\hline
\end{tabular}

Abbreviations: UL-EP, distance from upper lip to E line; LL-EP, distance from lower lip to $E$ line.

Figure 5 shows the distribution of evaluation scores of all varied images in the teams of the boy and girl. The average scores of the modified chromophotograph profile, F32 and F43, were greater than 6.0. The profiles, F31 and F42, had the same high score, which was more than 5.0. They were selected as the most pleasant profiles by judges.

According to Figure 5, there was a difference in the most attractive esthetic pattern for the boy and girl. The two images, the deviation of $-4 \mathrm{~mm}$ (F32) in the boy and the deviation of $-2 \mathrm{~mm}$ (F43) in girl, were considered as the most beautiful profiles. The esthetic pattern with a deviation of $+6 \mathrm{~mm}(\mathrm{~F} 37, \mathrm{~F} 47)$ from the line $\mathrm{E}$ was chosen as the least attractive. According to the Mann-Whitney test, in all the esthetic patterns, there was no significant difference in the evaluation scores among the sexes $(P>0.05)$ and age $(P>0.05)$, but regarding evaluators' education degree and clinical role, a statistical difference was found $(P<0.05)$.

The values of the distance, which refers to the upper and lower lip to the line E (mm) of the attractive image (F31, F32, F42, F43) evaluated by the judges, were measured. Table 5 shows the difference of the values before and after the image was modified.

Table 3 Description of the evaluators

\begin{tabular}{lll}
\hline Variables & $\mathbf{N}$ & $\%$ \\
\hline Sex & 90 & \\
Male & 160 & 36 \\
$\quad$ Female & & 64 \\
Age group & 150 & \\
I6-24 years & 65 & 60.0 \\
25-35 years & 35 & 26 \\
36-50 years & & 14 \\
Education degree & 82 & \\
Middle school & 114 & 32.8 \\
Undergraduate & 37 & 45.6 \\
Postgraduate & 17 & 14.8 \\
Doctor & & 6.8 \\
Clinic role & 43 & 17.2 \\
Middle student & 107 & 42.8 \\
Undergraduate & 50 & 20 \\
Orthodontic doctor & 50 & 20 \\
Parents & & \\
\hline
\end{tabular}




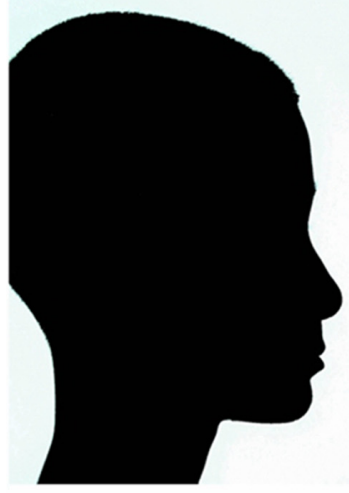

F11

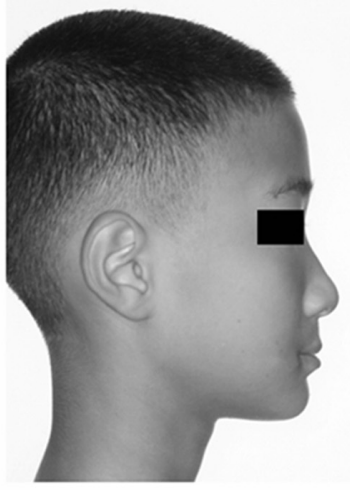

F12

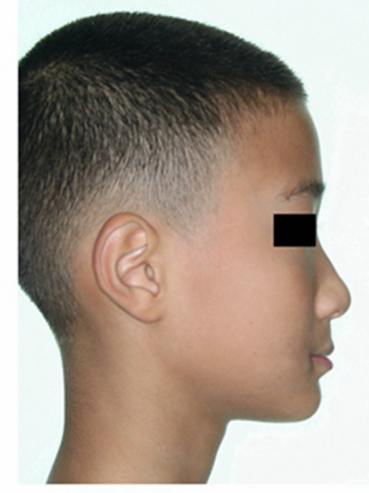

F13

Figure I Models of silhouette (FII), black and white photograph (FI2), and chromophotograph (FI3) of the same boy.

\section{Discussion}

An attractive profile may imply more opportunities to a person, and is often associated with some beautiful epithets, such as charming, kindhearted, and gentle. More and more attention is focused on the facial esthetic by the patients and professionals. ${ }^{5,13,14}$ Thus, the diagnostic and treatment method of soft tissue has been increasingly emphasized in orthodontic $^{5}$ and orthognathic surgery. ${ }^{11,15,16}$ McCollum and Evans ${ }^{11}$ pointed out that it is practical to first design and achieve the graceful soft tissue drape and appearance, then secondarily determine the surgical readjustments of the supporting bone tissue. This opinion was comprehensively approved and practiced by Worms et a ${ }^{15}$ and McCollum. ${ }^{16}$

In previous studies, ${ }^{5,6,9,10}$ the silhouette or black and white photograph was used to evaluate the profile. For soft tissue esthetic analysis, some researchers affirmed the use of silhouettes because it eliminates distractions so that one may focus on the patient's profile. On the other hand, some researchers liked the black and white photograph; they consider it as reflecting the facial features. ${ }^{5,6}$ But the authors of the present study took the chromophotograph into account because a harmonious face is a balanced and complementary match of the forehead, eyes, nose, lips, chin, neck curve, and ears, together with the color of the skin and hair. ${ }^{9}$ Yet, a silhouette or black and white photograph cannot reflect this. It is necessary to determine the influence of the color and texture of the photograph to the facial profile esthetic. In this study, we tried to determine the best method for evaluating a more esthetic profile by using the chromophotograph, black and white photograph, and silhouette.

The means of scores for the three groups of silhouettes, black and white photographs, and chromophotographs of the boy and girl are shown in Table 4 . We can see the score of the silhouette (team boy $=3.34 \pm 2.12$; team girl $=4.45 \pm 2.11)$ is not high; maybe the evaluators could experience the attractiveness of the contour outline, but not the face. The black and white photograph eliminated all the color of the texture on the face, but the score was the

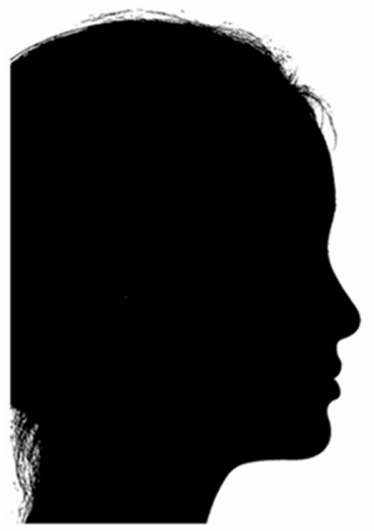

F21

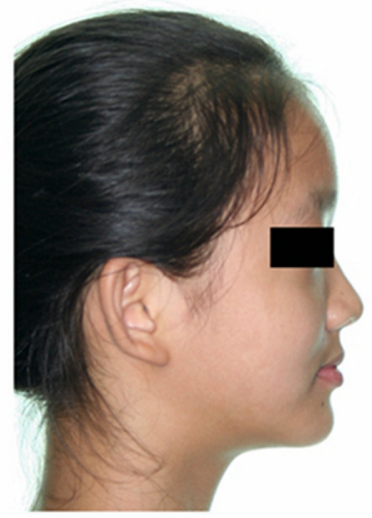

F23

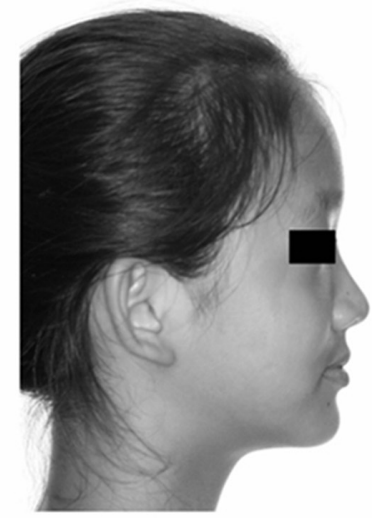

F22

Figure 2 Models of silhouette (F2I), black and white photograph (F22), and chromophotograph (F23) of the same girl. 
Table 4 Evaluation scores according to the profiles of the boy and girl

\begin{tabular}{lllll}
\hline Images & Silhouette & $\begin{array}{l}\text { Black and white } \\
\text { photograph }\end{array}$ & Chromophotograph & P-value \\
\cline { 2 - 3 } & Mean \pm SD & Mean \pm SD & Mean \pm SD & $<.47 \pm 1.53$ \\
\hline Boy & $3.34 \pm 2.12$ & $2.86 \pm 1.91$ & $5.93 \pm 1.93$ & $<0.001$ \\
Girl & $4.45 \pm 2.11$ & $3.12 \pm 2.21$ & $<.001$ \\
\hline
\end{tabular}

Abbreviation: SD, standard deviation.

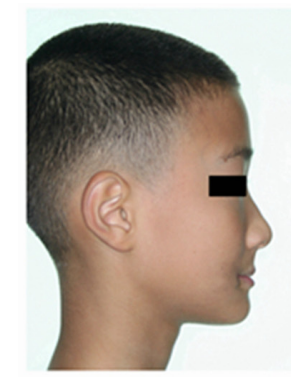

F31 -6 mm

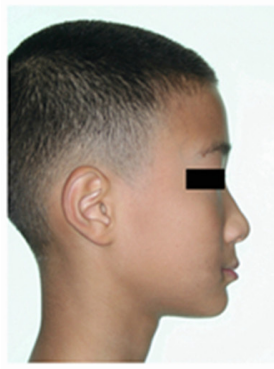

$\mathrm{F} 35+2 \mathrm{~mm}$

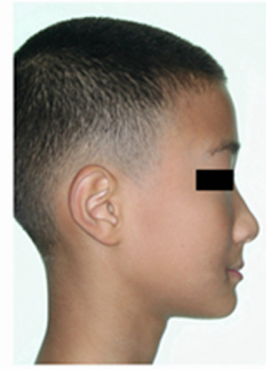

F32 -4 mm

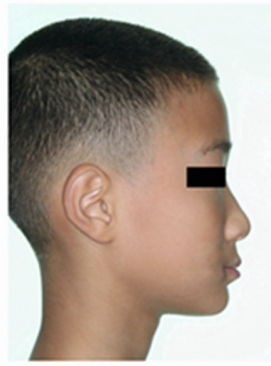

$\mathrm{F} 36+4 \mathrm{~mm}$

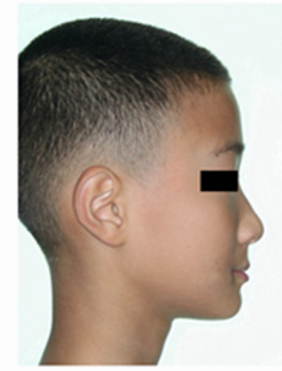

$\mathrm{F} 33-2 \mathrm{~mm}$

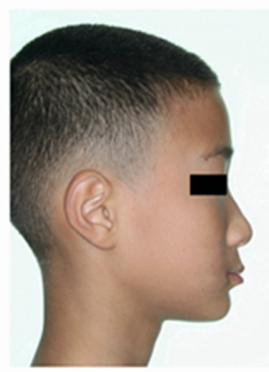

$\mathrm{F} 37+6 \mathrm{~mm}$

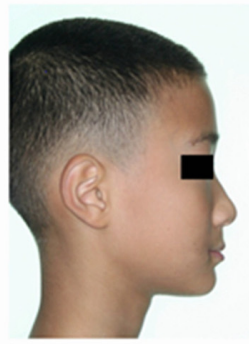

$\mathrm{F} 340 \mathrm{~mm}$

Figure 3 Models of chromophotograph of the boy with different lip positions (F3I-F37).

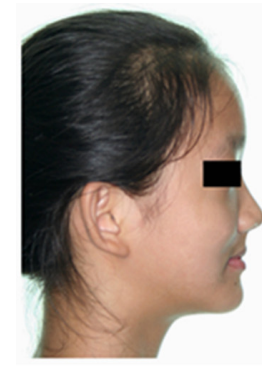

$\mathrm{F} 41-6 \mathrm{~mm}$

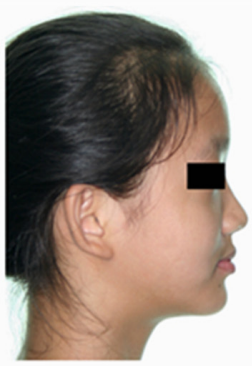

$\mathrm{F} 45+2 \mathrm{~mm}$

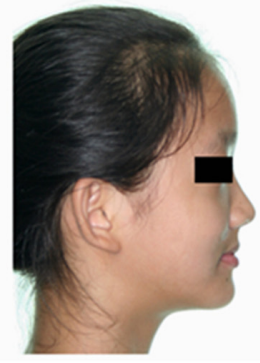

$\mathrm{F} 42-4 \mathrm{~mm}$

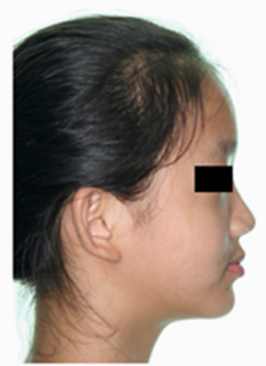

$\mathrm{F} 46+4 \mathrm{~mm}$

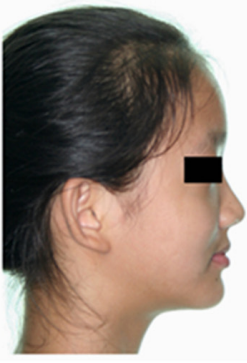

$\mathrm{F} 43-2 \mathrm{~mm}$

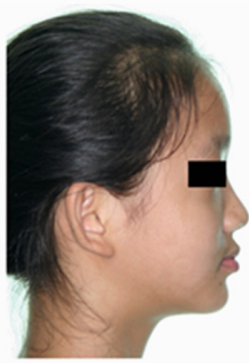

$\mathrm{F} 47+6 \mathrm{~mm}$

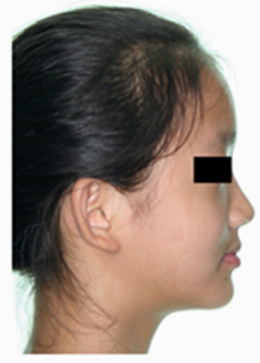

F44 $0 \mathrm{~mm}$

Figure 4 Models of chromophotograph of the girl with different lip positions (F4I-F47). 


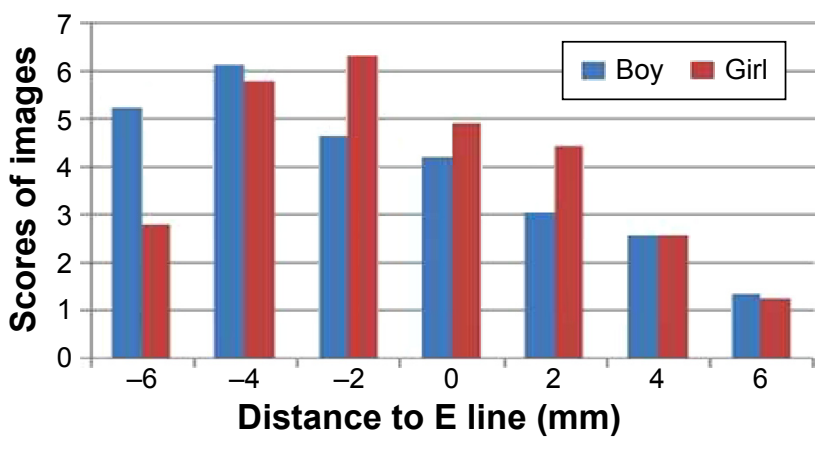

Figure 5 Evaluation scores according to the distance to $E$ line ( $\mathrm{mm}$ ).

lowest one (team boy $=2.86 \pm 1.91$; team girl $=3.12 \pm 2.21$ ). Whereas, the score of the chromophotograph was the highest one (team boy $=5.47 \pm 1.53$; team girl $=5.93 \pm 1.93$ ), and was regarded as the best way to express the profile by evaluators.

The beauty of a profile is tridimensional, and influenced by a harmony of the jaws and teeth accentuated on the face. Chromophotograph is close to real life, it is just whatever our eyes see. So, it bears a higher level of consistency from the majority of evaluators.

A balanced facial profile is also one of the main objectives of orthodontic treatment, especially the position of upper and lower lip and the nasal relationship of lip and chin. ${ }^{5}$ Zhao et $\mathrm{l}^{8}$ compared the Bolton standards of Chinese and Caucasians at the age of 13; they reported that the Chinese subjects presented a convex facial profile with a less prominent nose and chin. Hwang et $\mathrm{al}^{17}$ reported that the Korean laypersons preferred more concave profiles but the White respondents preferred more convex profiles. The esthetic plane, which means the line related to soft pogonion - the nose tip, created by Ricketts is widely used in the clinic because of its easy application to determine concave or convex shape among all the angles and lines. ${ }^{6}$ From Figure 5, we can see that the controlled lip position with a deviation of $-2 \mathrm{~mm}$ in the team of girl and a deviation of $-4 \mathrm{~mm}$ in the team of boy from the Ricketts' line E were chosen as the most beautiful profile by the evaluators. The profiles, F31 and F42, in both the teams of boy and girl had the same high score. So, Chinese also prefer the concave facial profile. This was the same result in the study conducted by Lim. ${ }^{18}$

According to Table 5, we can see that the boy had a distance of labrale superior at $-0.44 \mathrm{~mm}$ and labrale inferior at $-0.15 \mathrm{~mm}$ from Ricketts' line $\mathrm{E}$, and the girl had a labrale superior at $-0.65 \mathrm{~mm}$ and labrale inferior at -0.23 $\mathrm{mm}$ from the same line. The profile of the girls (F42, F43) was more concave than the boys (F31, F32), whereas the nose and chin appeared more convex. Maybe there is a difference in evaluation preference between boys and girls, but we need further research to clarify it. On the other hand, we also need to consider the individual difference of the prominence of the nose and chin. There is a need for more research to clarify.

The majority of studies invited the laypersons (undergraduates) or dentists who came from different sexual, racial, and educational backgrounds to evaluate the esthetic of the profile; they found that there was no significant difference between different people on evaluating the esthetic of the

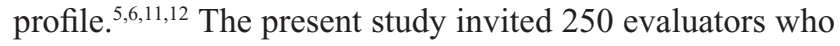
came from educational backgrounds, various ages and sex to judge the images. Miner et al reported that mothers had a smaller tolerance for change in the soft tissue profile than the clinicians or children. ${ }^{19}$ Patients and their parents care more about the esthetics of their profile as they are the subject in the survey whereas others viewing the photographs may not be so involved as they are third party. In this study, there were statistical differences among the variables of judges in their perception of the esthetic impact.

\section{Conclusion}

- In summary, the chromophotograph was selected as the best way to show the facial profile among the silhouettes, black and white photographs, and chromophotographs.

- The concave profile of the boy and girl was preferred by the judges, and the judges preferred the concave photo of the boy more than the concave profile of the girl, but this still needs further study to verify.

- There were differences in perception of esthetic among different judges.

Table 5 Values of the distance to the line $E(\mathrm{~mm})$ of the most attractive images, F32 and F45

\begin{tabular}{|c|c|c|c|c|c|c|c|c|}
\hline \multirow[t]{2}{*}{ Measurements } & \multirow{2}{*}{$\begin{array}{l}\text { Normal } \\
\text { mean }\end{array}$} & \multirow{2}{*}{$\begin{array}{l}\text { Standard } \\
\text { deviation }\end{array}$} & \multicolumn{2}{|c|}{ Before } & \multicolumn{4}{|l|}{ After } \\
\hline & & & Boy & Girl & F3I & F32 & F42 & F43 \\
\hline UL-EP, mm & -1.4 & 1.87 & -0.04 & -0.45 & -0.64 & -0.44 & -0.85 & -0.65 \\
\hline LL-EP, mm & 0.6 & 1.87 & +0.25 & -0.03 & -0.35 & -0.15 & -0.43 & -0.23 \\
\hline
\end{tabular}

Abbreviations: UL-EP, distance from upper lip to $E$ line; LL-EP, distance from lower lip to $E$ line. 


\section{Disclosure}

The authors report no conflicts of interest in this work.

\section{References}

1. Feldmann I. Satisfaction with orthodontic treatment outcome. Angle Orthod. 2014;84(4):581-587.

2. Erdinc AE, Nanda RS, Dandajena TC. Profile changes of patients treated with and without premolar extractions. Am J Orthod Dentofacial Orthop. 2007;132(3):324-331.

3. Perillo L, Esposito M, Caprioglio A, Attanasio S, Santini AC, Carotenuto M. Orthodontic treatment need for adolescents in the Campania region: the malocclusion impact on self-concept. Patient Prefer Adherence. 2014;19;8:353-359.

4. Perillo L, Masucci C, Ferro F, Apicella D, Baccetti T. Prevalence of orthodontic treatment need in southern Italian schoolchildren. Eur $J$ Orthod. 2010;32(1):49-53.

5. Pithon MM, Silva IS, Almeida IO, et al. Photos vs silhouettes for evaluation of profile esthetics between white and black evaluators. Angle Orthod. 2014;84(2):231-238.

6. Hockley A, Weinstein M, Borislow AJ, Braitman LE. Photos vs silhouettes for evaluation of African American profile esthetics. Am J Orthod Dentofacial Orthop. 2012;141(2):161-168.

7. Cooke MS, Wei SH. A comparative study of southern Chinese and British Caucasian cephalometric standards. Angle Orthod. 1989;59(2): 131-138.

8. Zhao XG, Hans MG, Palomo JM, Lin JX. Comparison of Chinese and white Bolton standards at age 13. Angle Orthod. 2013;83(5): 809-816.

9. Loi H, Yasutomi H, Nakata S, Nakasima A, Counts AL. Effect of lower facial vertical proportion on facial attractiveness in Japanese. Orthodontic Waves. 2006;65(4):161-165.
10. Kuroda S, Sugahara T, Takabatake S. Influence of anteroposterior mandibular positions on facial attractiveness in Japanese adult. $\mathrm{Am}$ J Orthod Dentofacial Orthop. 2009;135(1):73-78.

11. McCollum AG, Evans WG. Facial soft tissue: the alpha and omega of treatment planning in orthognathic surgery. Semin Orthod. 2009;15(3): 196-216.

12. Nola CF, Rodriguez-Chessa JG, Ortega-Lopes R. Prospective study of soft tissue contour changes following chin bone graft harvesting. Int $J$ Oral Maxillofac Surg. 2012;41(2):176-179.

13. Perillo L, Esposito M, Contiello M, Lucchese A, Santini AC, Carotenuto M. Occlusal traits in developmental dyslexia: a preliminary study. Neuropsychiatr Dis Treat. 2013;9:1231-1237.

14. Carotenuto M, Esposito M, Pascotto A. Facial patterns and primary nocturnal enuresis in children. Sleep Breath. 2011;15(2):221-227.

15. Worms FW, Isaacson RJ, Speidel TM. Surgical orthodontic treatment planning: profile analysis and mandibular surgery. Angle Orthod. 1976: 46(1):1-25.

16. McCollum TG. TOMAC: an orthognathic treatment planning system. Part I. Soft tissue analysis. J Clin Orthop. 2001;35(6):356-364.

17. Hwang HS, Kim WS, McNamara JA. Ethnic differences in the soft tissue profile of Korean and European-American adults with normal occlusions and well-balanced faces. Angle Orthod. 2002;72(1):72-80.

18. Lim HJ, Ko KT, Hwang HS. Esthetic impact of premolar extraction and nonextraction treatments on Korean borderline patients. Am J Orthod Dentofacial Orthop. 2008;133(4):524-531.

19. Miner RM, Anderson NK, Evans CA, Giddon DB. The perception of children's computer-imaged facial profiles by patients, mothers and clinicians. Angle Orthodontist. 2007;77(6):1034-1039.
Patient Preference and Adherence

\section{Publish your work in this journal}

Patient Preference and Adherence is an international, peer-reviewed, open access journal that focuses on the growing importance of patient preference and adherence throughout the therapeutic continuum. Patient satisfaction, acceptability, quality of life, compliance, persistence and their role in developing new therapeutic modalities and compounds to optimize

\section{Dovepress}

clinical outcomes for existing disease states are major areas of interest for the journal. This journal has been accepted for indexing on PubMed Central. The manuscript management system is completely online and includes a very quick and fair peer-review system, which is all easy to use. Visit http://www. dovepress.com/testimonials.php to read real quotes from published authors. 